Open Source Software for Digital Forensics 
Ewa Huebner - Stefano Zanero Editors

\section{Open Source Software for Digital Forensics}

望 Springer 


\section{Editors}

Ewa Huebner

Computer Forensis

Consulting, Warrimoo

NSW

Australia

ehuebner@computerforensis.com
Stefano Zanero

Dipto. Elettronica e Informazione (DEI)

Politecnico di Milano

Milano

Italy

zanero@elet.polimi.it

ISBN 978-1-4419-5802-0

e-ISBN 978-1-4419-5803-7

DOI 10.1007/978-1-4419-5803-7

Springer New York Dordrecht Heidelberg London

Library of Congress Control Number: 2010920822

(C) Springer Science+Business Media, LLC 2010

All rights reserved. This work may not be translated or copied in whole or in part without the written permission of the publisher (Springer Science+Business Media, LLC, 233 Spring Street, New York, NY 10013, USA), except for brief excerpts in connection with reviews or scholarly analysis. Use in connection with any form of information storage and retrieval, electronic adaptation, computer software, or by similar or dissimilar methodology now known or hereafter developed is forbidden.

The use in this publication of trade names, trademarks, service marks, and similar terms, even if they are not identified as such, is not to be taken as an expression of opinion as to whether or not they are subject to proprietary rights.

Printed on acid-free paper

Springer is part of Springer Science+Business Media (www.springer.com) 


\section{Preface}

This book is a collection of revised and extended chapters based on papers presented at the Open Source Software for Computer and Network Forensics (OSSCoNF) workshop, held in Milan in September 2008 at the World Computing Congress, co-located with the $4^{\text {th }}$ Open Source Software Conference, and some new work purposely commissioned for the book. It is aimed at scholars and free software authors, researchers, and digital forensics practitioners; it can serve both as a research archival resource, and an introductory text. To the best of our knowledge, it is the first research book totally oriented to the use of Free Libre Open Source Software (FLOSS) in digital forensics.

The purpose of the OSSCoNF workshop was twofold. First, we wished to determine the specific needs in computer and network forensics that are best addressed by the use and the creation of open source software. Secondly, we wished to give the authors a forum to present their tools and the research work that went into their design and development.

Similarly, this book consists of two parts, the first dealing with the motivations for using FLOSS in computer forensics today, and the second describing a number of tools (some that were presented at OSSCoNF), along with their evolution and some more extensive explanation of the details.

Part 1 consists of three chapters. In chapter 1 Zanero and Huebner discuss the importance of open source software in digital forensics with the focus on provably verifiable findings, and on easing reliance on expensive closed source software. Chapter 2 by Huebner, Bem and Cheung is dedicated to the application of the open source software tools in computer forensics education at tertiary level. The authors argue that open source tools are more suitable than commercial tools, as they provide the opportunity for students to gain in-depth understanding and appreciation of the computer forensic process. In chapter $3 \mathrm{Bem}$ explores the potential role of virtual environments in the analysis phase of computer forensics investigations, and proposes a method which may lead to a gradual shift to open source software.

Part 2 is dedicated to novel FLOSS tools for computer and network forensics, presented in five chapters. In chapter 4, Vermaas, Simons and Meijer describe the Open Computer Forensics Architecture (OCFA), an automated system that dissects complex file types, extracts metadata from files and ultimately creates indexes on forensic images of seized computers. Chapter 5 by Giustini, Andreolini and 
Colajanni presents CAINE (Computer Aided INvestigative Environment), a new GNU/Linux live distribution that contains a collection of tools wrapped up into a user friendly environment. In chapter 6, Gomez, Rojas and Mata describe VALI, a correlation model based on the concept of vector clocks to generate graphs showing the relationships between the reported events and possibly discovering unknown attack patterns. Chapter 7, by Cavalca and Goldoni, presents HIVE (Honeynet Infrastructure in Virtualized Environment), a novel highly scalable automated data collection and analysis architecture they designed. And finally, in chapter 7, Bassetti and Frati describe the Selective File Dumper, a Linux Bash script they developed to extract all the referenced, deleted and unallocated files and to perform a keyword search in a simple way.

We trust that you will find this collection educational and informative, and that it may encourage the reader to explore the existing FLOSS tools in digital forensics and to inspire future authors to create new innovative FLOSS tools for the forensic investigations community.

\section{Acknowledgments}

This book would not be possible without the assistance we received from others. First our thanks go to Professor Ernesto Damiani, the editor of the series, who suggested that we submit the expanded OSSCoNF workshop collection for publication as a book. We would also like to thank the people who help us in the review of chapters and served as a reference for the publishers. Here is the list of their names in alphabetical order:

Evangelos Markatos, University of Crete, Greece

Mattia Monga, University of Milan - DICO, Italy

Marcus Rogers, Purdue University, US

Siraj Ahmed Shaikh, Cranfield University, UK

Iain Sutherland, University of Glamorgan

Magdalena Szeżyńska, Warsaw University of Technology, Poland

Doug Wampler, Bellarmine University, US

Alec Yasinsac, Florida State University, US

And last but not least we would like to thank the editorial staff of Springer Science, especially Jennifer Maurer and Susan Lagerstrom-Fife, for the patience and understanding they showed us.

E. Huebner and S. Zanero 


\section{Contents}

\section{Part I Importance of FLOSS in Computer Forensics}

1 The Case for Open Source Software in Digital Forensics …….............. 3 Stefano Zanero and Ewa Huebner

2 Computer Forensics Education - the Open Source Approach .............. 9 Ewa Huebner, Derek Bem, and Hon Cheung

3 Virtual Machine for Computer Forensics - the Open Source Perspective

Derek Bem

\section{Part II Novel FLOSS Tools for Computer Forensics}

4 Open Computer Forensic Architecture a Way to Process Terabytes of Forensic Disk Images.

Oscar Vermaas, Joep Simons, and Rob Meijer

5 Open Source Live Distributions for Computer Forensics

Giancarlo Giustini, Mauro Andreolini, and Michele Colajanni

6 VALI: A Visual Correlation Tool Based on Vector Clocks.

Roberto Gomez, Julio Cesar Rojas, and Erika Mata

7 An Open Architecture for Distributed Malware Collection and Analysis

Davide Cavalca and Emanuele Goldoni

8 Selective File Dumper.

Nanni Bassetti and Denis Frati 